\title{
Prognostic significance of CD24 and claudin-7 immunoexpression in ductal invasive breast cancer
}

\author{
M.A. BERNARDI ${ }^{1}$, A.F. LOGULLO ${ }^{2}$, F.S. PASINI ${ }^{3}$, S. NONOGAKI ${ }^{4}$, \\ C. BLUMKE ${ }^{5}$, F.A. SOARES ${ }^{1}$ and M.M. BRENTANI ${ }^{1,3}$ \\ ${ }^{1}$ Mastology Department, A.C. Camargo Hospital; ${ }^{2}$ Pathology Department, Federal University of \\ São Paulo; ${ }^{3}$ Radiology and Oncology Department of Medical School, University of São Paulo; \\ ${ }^{4}$ Pathology Department, Adolfo Lutz Institute; ${ }^{5}$ Uninove University, São Paulo, Brazil
}

Received July 8, 2011; Accepted August 25, 2011

DOI: $10.3892 / o r .2011 .1477$

\begin{abstract}
This study aimed to identify the CD24 and CD44 immunophenotypes within invasive ductal breast carcinoma (IDC) subgroups defined by immunohistochesmistry markers and to determine its influence on prognosis as well as its association with the expression of $\mathrm{Ki}-67$, cytokeratins (CK5 and CK18) and claudin-7. Immunohistochemical expression of CD44 and CD24 alone or in combination was investigated in 95 IDC cases arranged in a tissue microarray (TMA). The association with subgroups defined as luminal A and B; HER2 rich and triple negative, or with the other markers and prognosis was analyzed. CD $44^{+} / \mathrm{CD} 24^{-}$and CD $44^{-} / \mathrm{CD} 24^{+}$were respectively present in $8.4 \%$ and $16.8 \%$ of the tumors, a lack of both proteins was detected in $6.3 \%$, while $\mathrm{CD} 44^{+} / \mathrm{CD} 24^{+}$ was observed in $45.3 \%$ of the tumors. Although there was no significant correlation between subgroups and different phenotypes, the $\mathrm{CD} 44^{+} / \mathrm{CD} 24^{-}$phenotype was more common in the basal subgroups but absent in HER 2 tumors, whereas luminal tumors are enriched in $\mathrm{CD} 44^{-} / \mathrm{CD} 24^{+}$and CD $44^{+} / \mathrm{CD} 24^{+}$cells. The frequency of $\mathrm{CD} 44^{+} / \mathrm{CD} 24^{-}$or $\mathrm{CD} 44^{-} / \mathrm{CD} 24^{+}$was not associated with clinical characteristics or biological markers. There was also no significant association of these phenotypes with the event free (DFS) and overall survival (OS). Single CD $44^{+}$was evident in $57.9 \%$ of the tumors and was marginally associated to grading and not to any other tumor characteristics as well as OS and DFS. CD24+ ${ }^{+}$was positive in $74.7 \%$ of the tumors, showing a significant association with estrogen receptor, progesterone receptor and $\mathrm{Ki}-67$ and a marginal association with CK18 and claudin-7. Expression of claudin-7 and $\mathrm{Ki}-67$ did not associate with the cancer subgroups, while a positive association between CK18 and the luminal subgroups
\end{abstract}

Correspondence to: Dr Maria Mitzi Brentani, Radiology and Oncology Department, Medical School of São Paulo University, Avenue Dr Arnaldo 455, 012406-903 São Paulo, Brazil

E-mail: mbrentani@lim24.fm.usp.br

Key words: cancer stem cell, CD24, CD44, claudin-7, prognosis, breast cancer subgroups was found ( $\mathrm{P}=0.03)$. CK5, CK18 and Ki-67 expression had no influence in OS or DFS. Single CD24+ $(\mathrm{P}=0.07)$ and claudin-7 positivity $(\mathrm{P}=0.05)$ were associated with reduced time of recurrence, suggesting a contribution of these markers to aggressiveness of breast cancer.

\section{Introduction}

Breast carcinoma is a disease which is known for its striking histopathological heterogeneity recognized for a long time and which is classified into several histological subtypes (1).

In recent years, molecular profiling technologies have provided further evidence that breast cancer is a heterogeneous disease at the molecular level. The major breast cancer biological subtypes have been defined by gene expression profiles (2) or histochemical biomarkers (3) and have led to a working model for breast cancer molecular taxonomy (4). According to this classification, breast cancers can be subdivided into luminal tumors expressing estrogen receptor (ER) and the progesterone receptor $(\mathrm{PR})\left(\mathrm{ER}^{+} / \mathrm{PR}^{+}\right)$which may be further subclassified into luminal $\mathrm{A}$ and luminal $\mathrm{B}$ tumors. The latter subtype exhibits either HER2 positivity or high expression of the proliferation marker Ki-67 (5). There are two ER/PR negative subtypes: HER2 rich (ER-/PR-/HER2 ${ }^{+}$), and triple negative (negative for the three markers). These subtypes of breast cancer show distinct behaviors related to prognosis, survival and response to specific therapies (1). Within the triple negative disease tumors two subtypes were identified: basal like and a new molecular subtype referred as claudin ${ }^{\text {low }}$ characterized by the low gene expression of claudins (claudin-4, claudin-7 and claudin-3) (6). It is possible that this heterogeneity is derived in part from the transformation of different subsets of stem/progenitor cells in each biological subtype as proposed by Dontu et al (7).

Cancer stem cells have been defined as a subset of tumor cells that display stem cell properties including self-renewal and differentiation, giving rise to several cell types in the tumor, contributing to its heterogeneity (8).

In breast cancer, a subpopulation of cells characterized by the surface markers $\mathrm{CD} 44^{+} / \mathrm{CD} 24^{\text {low }}$ has been reported to be highly tumorigenic when injected into immunocompromised mice (9). Shipitsin et al (10) reported that gene expression 
of $\mathrm{CD} 44^{+}$and $\mathrm{CD} 24^{+}$cells isolated from breast carcinomas exhibited distinct profiles and that the $\mathrm{CD}_{4} 4^{+}$profile showed genes consistent with a stem-cell like profile.

A correlation of the $\mathrm{CD} 44^{+} / \mathrm{CD} 24^{\text {low }}$ phenotype with specific breast cancer subtypes has been previously reported. This tumor phenotype appears to be common in basal like tumors $(11,12)$ and in triple negative tumors (13). It has been suggested that tumor cells with a CD $44^{+} \mathrm{CD} 24^{-}$subpopulation may have a worse clinical behavior $(13,14)$. In contrast, other studies have not revealed a significant association of $\mathrm{CD}_{4} 4^{+} /$ CD24- with a potential progress or recurrence $(15,16)$. As tumorigenesis involves complex biological mechanisms, Park et al (12) recently highlighted the need for evaluation of CD44/ CD24 in combination with other markers.

Our aim in the present study was to investigate the expression of CD44 and CD24 alone or in combination with a series of invasive ductal breast carcinomas arranged in a tissue microarray (TMA). Results were related to tumor subtypes defined by the immunohistochemical markers: ER and PR, HER2 and to the expression of $\mathrm{Ki}-67$, basal and luminal cytokeratins (CK5, CK6 and CK18) with special focus on the tight junction protein claudin-7. In addition, we investigated the clinicopathological and prognostic significance with respect to overall survival (OS) and disease-free survival (DFS) of the different combinations of CD44 and CD24 and of the analyzed biological markers.

\section{Materials and methods}

Subjects. The cohort was assembled from patients with primary ductal invasive breast carcinoma (IDC) diagnosed at the Instituto do Cancer Arnaldo Vieira de Carvalho between 2001 and 2007 after approval by its Institutional Review Board. A total of 95 cases were retrieved from the medical files, and the following patient information was collected: age, histological classification, nuclear grade, tumor size, node status, tumor recurrences, regional and distant metastasis, treatment, disease-free survival (DFS), and overall survival (OS). Patients were enrolled according to the inclusion criteria consisting of suitable paraffin blocks for immunohistochemistry, adequate clinicopathological data and sufficient follow-up. The Nottingham system was used for assessing tumor nuclear grading. In all IDC cases the treatment involved mastectomy, radiotherapy, chemotherapy and axillary lymph node dissection. Cases with a positive immunohistochemical ER analysis received hormone therapy. Median follow-up of the analyzed IDC cohort was 4.8 years. At the final follow-up (4.9 years), 66 (69.5\%) IDC patients were alive and $27(28.4 \%)$ died of the disease. Characteristics of this retrospective cohort are detailed in Table I.

TMA construction. For each case, all available hematoxylin and eosin (H\&E)-stained sections were reviewed to confirm the diagnosis of IDC and to select a representative tumor area for TMA construction and immunostaining.

For TMA construction, H\&E-stained slides from each paraffin-embedded tumor block were checked to select a morphologically representative tumor area, which was then selected to construct the TMA paraffin block. Two tissue cylinders of each case with a diameter of $1 \mathrm{~mm}$ were punched from
Table I. Clinicopathological properties of the breast carcinomas evaluated.

\begin{tabular}{|c|c|}
\hline Parameters & Patients $(\%)$ \\
\hline \multicolumn{2}{|l|}{ Age (years) } \\
\hline Median (range) & $58(28-88)$ \\
\hline \multicolumn{2}{|l|}{ Tumor size $(\mathrm{cm})$} \\
\hline Median (range) & $4.5(0.4-12.0)$ \\
\hline \multicolumn{2}{|l|}{ pTNM } \\
\hline I & $7(7.4)$ \\
\hline II & $41(43.2)$ \\
\hline III & $45(47.4)$ \\
\hline IV & $2(2.1)$ \\
\hline \multicolumn{2}{|l|}{ Nuclear grading } \\
\hline I & $2(2.1)$ \\
\hline II & $40(42.1)$ \\
\hline III & $52(54.7)$ \\
\hline ND & $1(1.1)$ \\
\hline \multicolumn{2}{|l|}{ Nodal status } \\
\hline Positive & $60(63.2)$ \\
\hline Negative & $33(34.7)$ \\
\hline ND & $2(2.1)$ \\
\hline \multicolumn{2}{|l|}{ Metastasis status } \\
\hline M1 & $21(22.1)$ \\
\hline M0 & $60(63.2)$ \\
\hline ND & $14(14.7)$ \\
\hline \multicolumn{2}{|l|}{ Condition } \\
\hline Alive & $66(69.5)$ \\
\hline Deceased & $27(28.4)$ \\
\hline ND & $2(2.1)$ \\
\hline
\end{tabular}

ND, not known.

the marked tumor areas of each of the 95 donor paraffin blocks and distributed into 4 new recipient paraffin blocks using the Manual Tissue Arrayer I (Beecher Instruments, Silver Spring, MD, USA). Sections ( $3 \mu \mathrm{m})$ were cut from the TMA paraffin block using the paraffin tape-transfer system (Instrumedics, St. Louis, MO, USA). One section was stained with H\&E to confirm the presence of the tumor by light microscopy, and standard slides were used for immunohistochemical analyses.

Immunohistochemistry. Monoclonal antibodies to CK5 (clone XM 26), CK6 (clone CHK6B), CK18 (clone DC10), PR (clone PgR636), Ki-67 (clone MIB1) and HER2 (polyclonal) were obtained from Dako (Dako, Denmark) and diluted 1:300, 1:100, 1:800, 1:500, 1:400, 1:2000, respectively. Each slide was also stained with 1:50 anti-ER (Neomarkers, clone 6F-11), claudin-7 diluted 1:500 (clone AB5487; Abcam, Cambridge, MA), CD44 (clone DF1485), raised against all forms of CD44, diluted 1:100 (Novocastra Laboratories Ltd., Newcastle, UK) and CD24 (clone C-20), diluted 1:100 (Santa Cruz Biotechnology, Palo Alto, CA, USA). 


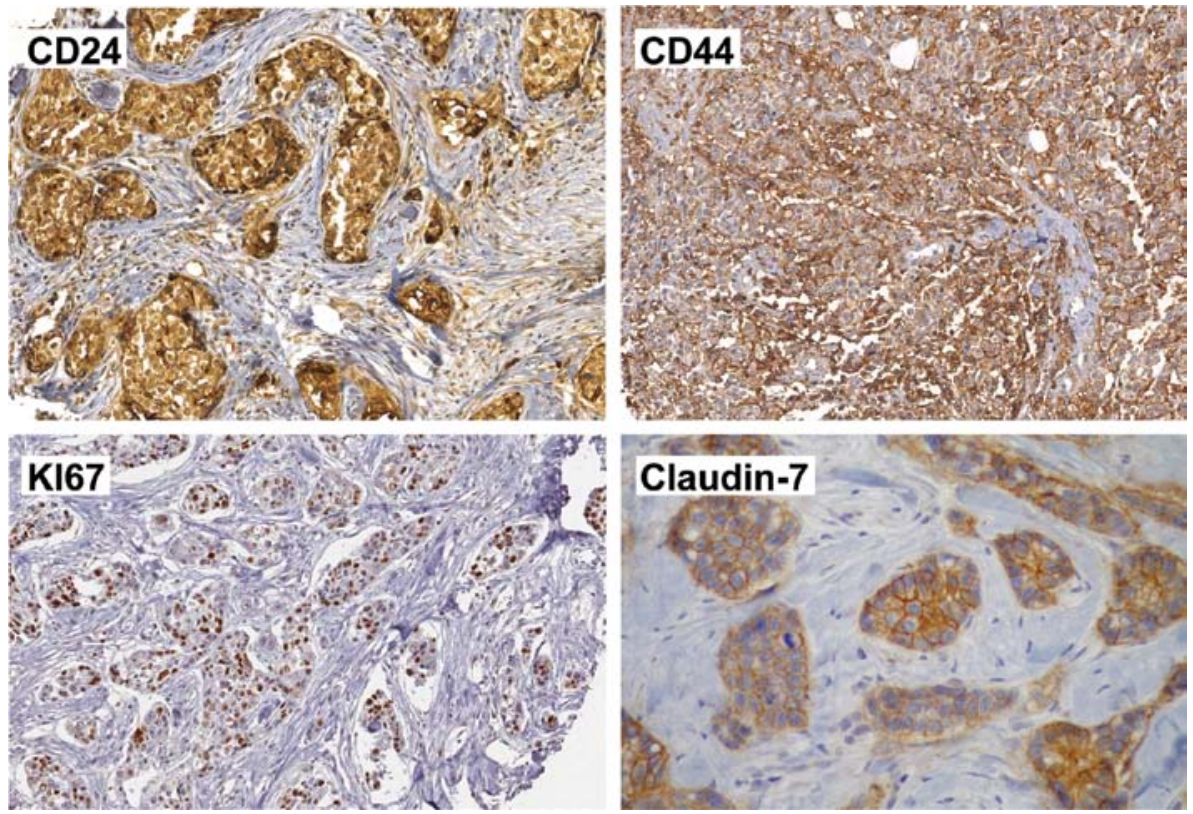

Figure 1. Immunopositivity of ductal invasive breast carcinomas for CD44, CD24, Ki-67 and claudin-7 (x200)

After deparaffinazation and rehydration of tissue microarray sections from formalin-fixed paraffin embedded samples, antigen retrieval was performed in a pressure cooker. After primary antibody incubation and secondary biotinylated streptavidin-peroxidase amplification, antigen detection was carried out by a solution containing 3,3' diaminobenzidine (Sigma, USA) and $6 \% \mathrm{H}_{2} \mathrm{O}_{2}$. Counterstaining was performed with Harris hematoxylin. Positive controls were included in each staining reaction and consisted of breast cancer known to express each of the antigens of interest.

An Allred score of ER and PR nuclear immunoreactivity $\leq 2$ was considered a negative result (17). For HER2 samples, lack of reactivity in $<10 \%$ of the tumor cells was scored as 0 . Barely perceptible focal membrane staining was scored as 1 . Weak to moderate staining observed in $>10 \%$ of the tumor cells was defined as 2 . Strong staining of the complete membrane in $>10 \%$ of the tumor cells was scored as 3 . Staining was considered positive only if samples scored $3^{+}$according to the American Society of Clinical Oncology of American Pathologists recommendation. For basal cytokeratins (CK 5/6) and claudin-7, samples were considered positive if $\geq 10 \%$ of tumor cells were reactive.

Specimens that exhibited a positive staining in $\geq 20 \%$ of cells were considered as Ki-67 positive. Negative controls were performed by omission of the respective primary antibody. Normal breast tissue usually presents $2^{+}$pattern of claudin-7 expression and $1^{+}$or 0 of CD24 and CD44. Therefore, $3^{+}$ usually represents overexpression.

CD44 and claudin-7 were considered positive when membranes were stained in a distinct and delicate pattern without reactive cytoplasm or nuclei. We used a HERcept test model for reporting results and the scoring was: 0 , totally negative; $1^{+}, 1-10 \%$ positive neoplastic cells; $2^{+}$, moderate staining in $10-30 \%$ of neoplastic cells; and $3^{+},>30 \%$ of strongly reactive neoplastic cells. CD24 was detected mainly in the cytoplasm and scoring was conducted as for CD44. Normal breast tissue usually presents a $2^{+}$pattern of claudin-7 expression and $1^{+}$ or 0 for CD24 and CD44. Therefore, $3^{+}$usually represents overexpression.

For the prognostic investigation and survival analysis, each individual immunophenotype pattern was evaluated for single CD $44^{+}$(CD44 positive cells), single CD24+ (CD24 positive cells) and four combinations, CD $44^{+} / \mathrm{CD} 24^{+}, \mathrm{CD} 44^{-} / \mathrm{CD} 24^{-}$, CD $44^{+} / \mathrm{CD} 24^{-}, \mathrm{CD} 44^{-} / \mathrm{CD} 24^{+}$.

Statistical methods. Correlation between antigen expression and other clinicopathological parameters was examined by the $\chi^{2}$ test. Survival probabilities were estimated by the univariate Kaplan-Meier method, survival curves were compared by the log-rank (Mantel-Haenszel method). SSPS version 10.0 for Windows was used. Statistical significance was set at $\mathrm{p}<0.05$.

\section{Results}

A total of 95 patients with IDC were evaluated. The demographic and clinical data are summarized in Table I.

The frequency of the biological markers analyzed is shown in Table II. Nuclear immunoreactivity for ER and PR and $\mathrm{Ki}-67$ was expressed in $47.4 \%$ and HER2 in $34.7 \%$ of the cases. Claudin-7 was detected in $38.9 \%$, basal cytokeratin 5 in $17.9 \%$ and CK18 in $61.1 \%$ of the cases. Tumors were mostly positive for either CD44 (57.9\%) or CD24 (74.7\%).

The pattern of CD44 expression was mainly membranous whereas CD24 was expressed predominantly in the cytoplasm. Claudin-7 was also expressed at the membrane and Ki-67 immunostaining was exclusively nuclear. Positive cytokeratins 5 and 18 were found in 17.9 and $61.1 \%$ of the cases, respectively. CK6 was expressed in only $2.1 \%$ of the cases. Examples of immunoreactivity of CD $44^{+}, \mathrm{CD} 24^{+}, \mathrm{Ki}-67$ and claudin-7 are displayed in Fig. 1.

To determine if the expression of CD44 and CD24 is associated with tumor characteristics the clinicopathological 
Table II. Frequency of immunostaining among arrayed breast carcinoma cases.

\begin{tabular}{|c|c|}
\hline Parameters & Patients $(\%)$ \\
\hline \multicolumn{2}{|l|}{ Estrogen receptor } \\
\hline Positive & $45(47.4)$ \\
\hline Negative & $35(36.8)$ \\
\hline ND & $15(15.8)$ \\
\hline \multicolumn{2}{|c|}{ Progesterone receptor } \\
\hline Positive & $45(47.4)$ \\
\hline Negative & $35(36.8)$ \\
\hline ND & $15(15.8)$ \\
\hline \multicolumn{2}{|l|}{ HER2 } \\
\hline Positive & $33(34.7)$ \\
\hline Negative & $51(53.7)$ \\
\hline ND & $11(11.6)$ \\
\hline \multicolumn{2}{|l|}{$\mathrm{Ki}-67$} \\
\hline Positive & $45(47.4)$ \\
\hline Negative & $40(42.1)$ \\
\hline ND & $10(10.5)$ \\
\hline \multicolumn{2}{|l|}{ CD44 } \\
\hline Positive & $55(57.9)$ \\
\hline Negative & $23(24.2)$ \\
\hline ND & $17(17.9)$ \\
\hline \multicolumn{2}{|l|}{ Phenotypes } \\
\hline $\mathrm{CD} 44^{+} / \mathrm{CD} 24^{+}$ & $43(45.3)$ \\
\hline $\mathrm{CD} 44^{+} / \mathrm{CD} 24^{-}$ & $8(8.4)$ \\
\hline $\mathrm{CD} 44^{-} / \mathrm{CD} 24^{+}$ & $16(16.8)$ \\
\hline $\mathrm{CD} 44^{-} / \mathrm{CD} 24^{-}$ & $6(6.3)$ \\
\hline ND & $22(23.2)$ \\
\hline \multicolumn{2}{|l|}{$\mathrm{CD} 24$} \\
\hline Positive & $71(74.7)$ \\
\hline Negative & $19(20.0)$ \\
\hline ND & $5(5.3)$ \\
\hline \multicolumn{2}{|l|}{ Claudin-7 } \\
\hline Positive & $37(38.9)$ \\
\hline Negative & $49(51.6)$ \\
\hline ND & $9(9.5)$ \\
\hline \multicolumn{2}{|l|}{ CK5 } \\
\hline Positive & $17(17.9)$ \\
\hline Negative & $68(71.6)$ \\
\hline ND & $10(10.5)$ \\
\hline \multicolumn{2}{|l|}{ CK6 } \\
\hline Positive & $2(2.1)$ \\
\hline Negative & $80(84.2)$ \\
\hline ND & $13(13.7)$ \\
\hline \multicolumn{2}{|l|}{ CK18 } \\
\hline Positive & $58(61.1)$ \\
\hline Negative & $27(28.4)$ \\
\hline ND & $10(10.5)$ \\
\hline
\end{tabular}

Table II. Continued.

\begin{tabular}{lc}
\hline Parameters & Patients $(\%)$ \\
\hline Subgroups & \\
Luminal A & $24(25.3)$ \\
Luminal B & $23(24.2)$ \\
HER2 & $9(9.5)$ \\
Triple negative & $20(21.5)$ \\
ND & $19(20.0)$ \\
\hline
\end{tabular}

HER2, human epidermal growth factor receptor 2; CK, cytokeratin; ND, not known.

features and biological markers were compared in the CD44 and CD24 positive and negative cases (Table III).

Presence of CD44 was not associated with ER, PR, Ki-67, claudin-7 nor with clinical characteristics, but a marginal association with high grade $(\mathrm{P}=0.08)$ was observed (Table III). Positive expression of $\mathrm{CD} 24$ was associated with $\mathrm{ER}(\mathrm{P}=0.05)$, $\mathrm{PR}(\mathrm{P}=0.02)$ and $\mathrm{Ki}-67$ positivity $(\mathrm{P}=0.01)$. There was a trend although not statistically significant, for the presence of CD24 to correlate with claudin-7 and CK18.

Cases were categorized into four phenotypes according to CD44 and CD24 positive/negative expression. Of the 95 patients, $8(8.4 \%)$ were categorized into the $\mathrm{CD} 44^{+} / \mathrm{CD} 24^{-}$ phenotype; the proportion of double positive $\left(\mathrm{CD} 44^{+} / \mathrm{CD} 24^{+}\right)$ and double negative (CD44\% ${ }^{-}$CD24-)tumors was $43(45.3 \%)$ and $6(6.3 \%)$ respectively, while the $\mathrm{CD} 44^{-} / \mathrm{CD} 24^{+}$phenotype was detected in $16.8 \%$ of the tumors (Table II).

We used an immunohistochemical surrogate for the gene array expression to define the subgroups of breast carcinoma. Among 95 IDC, a total of 47 tumors were categorized within the luminal subgroups: luminal A $(25.3 \%)$ and luminal B $(24.2 \%) ; 20(21.5 \%)$ of 95 had a triple negative profile and the HER2 subgroup contributed to $9.5 \%$ of the tumors (Table II).

Next, we explored the expression of CD44/CD24 phenotypes across the breast cancer subgroups (Table IV). No association with a particular subtype of breast cancer was observed. However, CD $44^{+} / \mathrm{CD} 24^{-}$expression was more common in the triple negative subgroup, absent in the HER2 $2^{+}$group and presented a low frequency in the luminal B subgroup (10\%). Double positive tumors were more frequent in the luminal subgroups, and we noted that these subgroups contained a high proportion of CD $44^{-} / \mathrm{CD} 24^{+}$cells. Our evaluation did not show any association of the frequency of different phenotypes with the clinicopathological parameters, pTNM stage, lymph node status, CK7, CK5, CK18, claudin-7 expression. However, we observed a marginal association $(\mathrm{P}=0.08)$ of a high proportion of double positive cases with high nuclear grade and of Ki-67 positive frequency with $\mathrm{CD} 44^{-} / \mathrm{CD} 24^{+}$tumors $(\mathrm{P}=0.06)$. Concerning the association with the frequency of metastasis, the higher frequency was related to the $\mathrm{CD} 44^{+} / \mathrm{CD} 24^{+}$phenotype $(82.4 \%)$ followed in descending order by CD $44^{-} / \mathrm{CD} 24^{+}$ (11.8\%), CD44-/CD24- (5.9\%) and $\mathrm{CD}^{+} / \mathrm{CD} 24^{-}(0 \%)$.

We also evaluated whether the expression of claudin-7, Ki-67, CK5 and CK18 differed in the tumor subgroups (Table V). Results indicated a similar frequency of Ki-67 
Table III. Association of CD44 and CD24 expression in breast carcinomas with clinicopathological characteristics and biological markers.

\begin{tabular}{|c|c|c|c|c|c|c|}
\hline \multirow[b]{2}{*}{ Parameters } & \multicolumn{2}{|c|}{ CD44 } & \multirow[b]{2}{*}{ P-value } & \multicolumn{2}{|c|}{$\mathrm{CD} 24$} & \multirow[b]{2}{*}{ P-value } \\
\hline & Negative $(\%)$ & Positive (\%) & & Negative $(\%)$ & Positive $(\%)$ & \\
\hline \multicolumn{7}{|l|}{ pTNM } \\
\hline $\mathrm{I} / \mathrm{II}$ & $14(35.0)$ & $26(65.0)$ & 0.31 & $13(28.3)$ & $33(71.7)$ & 0.12 \\
\hline III & $8(22.2)$ & $28(77.8)$ & & $6(14.0)$ & $37(86.0)$ & \\
\hline \multicolumn{7}{|c|}{ Nuclear grading } \\
\hline I & $0(0)$ & $2(100.0)$ & & $1(50.0)$ & $1(50.0)$ & \\
\hline II & $14(41.2)$ & $20(58.8)$ & 0.08 & $8(21.6)$ & $29(78.4)$ & 0.52 \\
\hline III & $8(19.5)$ & $33(80.5)$ & & $9(18.0)$ & $41(82.0)$ & \\
\hline \multicolumn{7}{|l|}{ Nodal status } \\
\hline Positive & $16(34.0)$ & $31(66.0)$ & 0.30 & $13(22.8)$ & $44(77.2)$ & 0.79 \\
\hline Negative & $6(20.7)$ & $23(79.3)$ & & $6(18.8)$ & $26(81.3)$ & \\
\hline \multicolumn{7}{|c|}{ Estrogen receptor } \\
\hline Positive & $11(26.2)$ & $31(73.8)$ & 0.79 & $5(11.4)$ & $39(88.6)$ & 0.05 \\
\hline Negative & $9(31.0)$ & $20(69.0)$ & & $10(30.3)$ & $23(69.7)$ & \\
\hline \multicolumn{7}{|c|}{ Progesterone receptor } \\
\hline Positive & $7(21.9)$ & $25(78.1)$ & 0.42 & $2(6.1)$ & $31(93.9)$ & 0.02 \\
\hline Negative & $12(32.4)$ & $25(67.6)$ & & $12(27.3)$ & $32(72.7)$ & \\
\hline \multicolumn{7}{|l|}{ HER2 } \\
\hline Positive & $6(19.4)$ & $25(80.6)$ & 0.12 & $5(16.7)$ & $25(83.3)$ & 1.00 \\
\hline Negative & $16(39.0)$ & $25(61.0)$ & & $10(19.6)$ & $41(80.4)$ & \\
\hline \multicolumn{7}{|l|}{$\mathrm{Ki}-67$} \\
\hline Positive & $13(31.0)$ & $29(69.0)$ & 1.00 & $4(9.3)$ & 39 (90.7) & 0.01 \\
\hline Negative & $9(28.1)$ & $23(71.9)$ & & $13(33.3)$ & $26(66.7)$ & \\
\hline \multicolumn{7}{|l|}{ Claudin-7 } \\
\hline Positive & $6(18.8)$ & $26(81.3)$ & 0.12 & $4(11.8)$ & $30(88.2)$ & 0.17 \\
\hline Negative & $15(35.7)$ & $27(64.3$ & & $13(26.5)$ & $36(73.5)$ & \\
\hline \multicolumn{7}{|l|}{ CK5 } \\
\hline Positive & $4(28.6)$ & $10(71.4)$ & 1.00 & $2(12.5)$ & $14(87.5)$ & 0.51 \\
\hline Negative & $17(28.8)$ & $42(71.2)$ & & $14(21.5)$ & $51(78.5)$ & \\
\hline \multicolumn{7}{|l|}{ CK6 } \\
\hline Positive & $0(0)$ & $2(100.0)$ & 1.00 & $0(0)$ & $1(100.0)$ & 1.00 \\
\hline Negative & $19(27.9)$ & $49(72.1)$ & & $14(18.2)$ & $63(81.8)$ & \\
\hline \multicolumn{7}{|l|}{ CK18 } \\
\hline Positive & $12(24.5)$ & $37(75.5)$ & 0.28 & $9(15.8)$ & $48(84.2)$ & 0.14 \\
\hline Negative & $9(37.5)$ & $15(62.5)$ & & $8(32.0)$ & $17(68.0)$ & \\
\hline
\end{tabular}

HER2, human epidermal growth factor receptor 2; CK, cytokeratin; ${ }^{\text {a }}$ statistical significance was determined by the $\chi^{2}$ test. P-values (two-sided) $<0.05$ were considered statistically significant and are indicated in bold.

$(\mathrm{P}=0.47)$ in all 4 subgroups; cytokeratin 18 (CK18) expression was clearly associated to the luminal cases $(\mathrm{P}=0.003)$ and CK5 positivity was more common in HER 2 and triple negative tumors $(\mathrm{P}=0.1)$. However, only $30 \%(\mathrm{n}=4)$ of the triple negative tumors displayed CK5 immunoreactivity, emphasizing the small number of basal tumors in our tumor material. Positive claudin-7 was less frequent in the triple negative subgroup.
Claudin-7 was not associated with known prognostic parameters such as pTNM, nuclear grade or nodal status, but on the other hand, showed a trend toward the presence of metastasis $(\mathrm{P}=0.07)$. Claudin-7 was very likely to be positive in HER2 positive tumors $(\mathrm{P}=0.07)$, and was inversely associated to progesterone receptor $(\mathrm{P}=0.02)$ and $\mathrm{CK} 5$ presence $(\mathrm{P}=0.03)$ (Table VI). 
Table IV. Distribution of phenotypes according to immunohistochemically-defined subgroups of invasive ductal carcinomas, clinicopathological features and biological markers.

\begin{tabular}{|c|c|c|c|c|c|}
\hline Parameters & $\begin{array}{c}\mathrm{CD} 44^{+} / \mathrm{CD} 24^{+} \\
\mathrm{n}(\%)\end{array}$ & $\begin{array}{c}\mathrm{CD}^{4} 4^{+} / \mathrm{CD} 24^{-} \\
\mathrm{n}(\%)\end{array}$ & $\begin{array}{c}\mathrm{CD} 44^{-} / \mathrm{CD} 24^{+} \\
\mathrm{n}(\%)\end{array}$ & $\begin{array}{c}\mathrm{CD} 44^{-} / \mathrm{CD} 24- \\
\mathrm{n}(\%)\end{array}$ & $\mathrm{P}$-value ${ }^{\mathrm{a}}$ \\
\hline \multicolumn{6}{|l|}{ Luminal A } \\
\hline $\mathrm{HER}^{-} / \mathrm{ER}^{+}$or $\mathrm{PR}^{+}$ & $12(57.1)$ & $1(4.8)$ & $7(33.3)$ & $1(4.8)$ & \\
\hline \multicolumn{6}{|l|}{ Luminal B } \\
\hline $\mathrm{HER}^{+} / \mathrm{ER}^{+}$or $\mathrm{PR}^{+}$ & $14(70.0)$ & $2(10.0)$ & $3(15.0)$ & $1(5.0)$ & 0.30 \\
\hline $\mathrm{HER}^{+} / \mathrm{ER}^{-}$and $\mathrm{PR}^{-}$ & $6(85.7)$ & $0(0)$ & $0(0)$ & $1(14.3)$ & \\
\hline Triple negative & $7(38.9)$ & $4(22.2)$ & $5(27.8)$ & $2(11.1)$ & \\
\hline \multicolumn{6}{|l|}{ pTNM } \\
\hline $\mathrm{I}+\mathrm{II}$ & $21(55.3)$ & $4(10.5)$ & $7(18.4)$ & $6(15.8)$ & 0.12 \\
\hline III & $22(64.7)$ & $4(11.8)$ & $8(23.5)$ & $0(0)$ & \\
\hline \multicolumn{6}{|l|}{ Nuclear grading } \\
\hline I & $1(50.0)$ & $1(50.0)$ & $0(0)$ & $0(0)$ & 0.08 \\
\hline II & $16(51.6)$ & $2(6.5)$ & $8(25.8)$ & $5(16.1)$ & \\
\hline III & $26(66.7)$ & $5(12.8)$ & $8(20.5)$ & $0(0)$ & \\
\hline \multicolumn{6}{|l|}{ Nodal status } \\
\hline Positive & $25(56.8)$ & $4(9.1)$ & $10(22.7)$ & $5(11.4)$ & 0.57 \\
\hline Negative & $18(64.3)$ & $4(14.3)$ & $5(17.9)$ & $1(3.6)$ & \\
\hline \multicolumn{6}{|l|}{ Metastasis } \\
\hline M0 & $24(53.3)$ & $7(15.6)$ & $10(22.2)$ & $4(8.9)$ & 0.16 \\
\hline M1 & $14(82.4)$ & $0(0)$ & $2(11.8)$ & $1(5.9)$ & \\
\hline \multicolumn{6}{|l|}{$\mathrm{Ki}-67$} \\
\hline Positive & $24(60.0)$ & $3(7.52)$ & $12(30.0)$ & $1(42.1)$ & 0.06 \\
\hline Negative & $17(54.8)$ & $5(16.1)$ & $4(12.9)$ & $5(16.1)$ & \\
\hline \multicolumn{6}{|l|}{ Claudin-7 } \\
\hline Positive & $20(69.0)$ & $3(10.3)$ & $5(17.2)$ & $1(3.4)$ & 0.5 \\
\hline Negative & $22(52.4)$ & 5 (11.9) & $11(26.2)$ & $4(9.5)$ & \\
\hline \multicolumn{6}{|l|}{ CK5 } \\
\hline Positive & $8(61.5)$ & $1(7.7)$ & $3(23.1)$ & $1(7.7)$ & 0.98 \\
\hline Negative & $34(60.7)$ & $6(10.7)$ & 11 (19.6) & $5(8.9)$ & \\
\hline \multicolumn{6}{|l|}{ CK18 } \\
\hline Positive & $32(66.7)$ & $4(8.3)$ & $9(18.8)$ & $3(6.3)$ & 0.22 \\
\hline Negative & $9(40.9)$ & 4 (18.2) & $6(27.3)$ & 3 (13.6) & \\
\hline
\end{tabular}

HER2, human epidermal growth factor receptor; ER, estrogen receptor; PR, progesterone receptor; CK, cytokeratin; ${ }^{\text {a }}$ statistical significance was determined by the $\chi^{2}$ test. P-value (two-sided) $<0.05$ was considered statistically significant.

To determine whether CD24 and CD44 and their combined phenotypes may affect overall survival (OS) and disease-free survival (DFS), we constructed Kaplan-Meier survival curves which were analyzed statistically (log-rank test). The median follow-up for this study was 4.8 years (range, $0.36-10.9$ years).

When the analysis was performed according to the frequency of combined phenotypes we found that they did not have an impact on patient DFS or OS. However, we observed that the $\mathrm{CD} 44^{+} / \mathrm{CD} 24^{-}$phenotype was more favorable with respect to OS $(87.5 \%$ of patients alive) or DFS (100\% without metastasis) while the $\mathrm{CD} 44^{-} / \mathrm{CD} 24^{+}$phenotype indicated a poorer survival $(53.3 \%$ of alive patients) and reduced DFS (83\% without metastasis).

No influence of CD $44^{+}$immunophenotype on OS or DFS was observed. Considering the single CD $24^{+}$phenotype we noted no association with OS, but there was a significant association to a reduction of DFS, although a border line one $(\mathrm{P}=0.07)$. CK5, CK18 and Ki-67 expression had no influence in OS or DFS. However, claudin-7 positivity although not statistically associated with OS, was associated with reduced DFS. $62.9 \%$ for positive claudin-7 vs. $82.5 \%$ for claudin-7 negative $(\mathrm{P}=0.05)$. Claudin-7 positivity was also related to a 
Table V. Distribution of biological markers in accordance with the molecular subgroups defined by immunohistochemical features of breast carcinoma.

\begin{tabular}{|c|c|c|c|c|c|}
\hline Parameters & $\begin{array}{c}\text { Luminal A } \\
\left(\mathrm{HER} 2-/ \mathrm{ER}^{+} \text {or } \mathrm{PR}^{+}\right) \\
\mathrm{n}(\%)\end{array}$ & $\begin{array}{c}\text { Luminal B } \\
\left(\mathrm{HER}^{+} / \mathrm{ER}^{+} \text {or } \mathrm{PR}^{+}\right) \\
\mathrm{n}(\%)\end{array}$ & $\begin{array}{c}\mathrm{HER}^{+} / \mathrm{ER}^{-} \text {and } \mathrm{PR}^{-} \\
\mathrm{n}(\%)\end{array}$ & $\begin{array}{c}\text { Triple negative } \\
\mathrm{n}(\%)\end{array}$ & P-value ${ }^{a}$ \\
\hline \multicolumn{6}{|l|}{ Claudin-7 } \\
\hline Positive & $11(45.8)$ & 14 (60.9) & $5(55.6)$ & $6(30.0)$ & 0.22 \\
\hline Negative & $13(54.2)$ & $9(44.4)$ & $4(44.4)$ & $14(70.0)$ & \\
\hline \multicolumn{6}{|l|}{$\mathrm{Ki}-67$} \\
\hline Positive & $14(60.9)$ & $15(65.2)$ & $5(55.6)$ & $8(42.1)$ & 0.47 \\
\hline Negative & $9(39.1)$ & $8(34.8)$ & $4(44.4)$ & $11(57.9)$ & \\
\hline \multicolumn{6}{|l|}{ CK5 } \\
\hline Positive & $4(17.4)$ & $2(8.7)$ & $4(44.4)$ & $6(31.6)$ & 0.10 \\
\hline Negative & $19(82.6)$ & $21(91.3)$ & $5(55.6)$ & $13(68.4)$ & \\
\hline \multicolumn{6}{|l|}{ CK18 } \\
\hline Positive & $18(78.3)$ & $20(87.0)$ & $5(55.6)$ & $7(36.8)$ & 0.003 \\
\hline Negative & $5(21.7)$ & $3(13.0)$ & $4(44.4)$ & $12(63.2)$ & \\
\hline \multicolumn{6}{|l|}{ Nodal status } \\
\hline Positive & $17(73.9)$ & $12(54.5)$ & $6(66.7)$ & $12(60.0)$ & 0.58 \\
\hline Negative & $6(26.1)$ & $10(45.5)$ & $3(33.3)$ & $8(40.0)$ & \\
\hline \multicolumn{6}{|l|}{ pTNM } \\
\hline I & $2(8.3)$ & $3(13.0)$ & $1(11.1)$ & $1(5.0)$ & 0.96 \\
\hline II & $9(37.5)$ & $10(43.5)$ & $4(44.4)$ & $9(45.0)$ & \\
\hline III & $13(54.2)$ & $9(39.1)$ & $4(44.4)$ & $9(45.0)$ & \\
\hline IV & 0 & $1(4.3)$ & $0(0.0)$ & $1(5.0)$ & \\
\hline \multicolumn{6}{|l|}{ Metastasis } \\
\hline M0 & 14 (63.6) & $16(84.2)$ & $1(14.3)$ & $15(75)$ & 0.05 \\
\hline M1 & $8(33.3)$ & $3(13.0)$ & $13(13.0)$ & $2(10.0)$ & \\
\hline
\end{tabular}

HER2, human epidermal growth factor receptor 2; astatistical significance was determined by the $\chi^{2}$ test. A P-value (two-sided) $<0.05$ was considered statistically significant and is indicated in bold.

higher frequency of metastatic tumors $(65 \%)$ as compared to claudin-7 negativity $(40 \%, \mathrm{P}=0.07)$. When we analyzed the distribution of cases relative to their subgroup profiles, we observed a larger proportion of patients who died or relapsed in the HER2 subgroup ( $\mathrm{P}=0.03)$ within the follow-up period, whereas no differences in OS or DFS was verified among the other subgroups (Figs. 2 and 3).

\section{Discussion}

In this study we used a tissue microarray to examine the expression of hormone receptors and HER 2 in 95 cases of invasive ductal carcinoma and categorized these cases into subgroups based on immunohistochemistry analysis. Next, we determined the expression of CD44 and CD24 in our tumor series and analyzed the association of these phenotypes with the different subgroups.

We found that luminal groups were the most common immunohistochemical subtypes within the range of other studies. There was also no significant association between subtypes and clinicopathological features, consistent with previous reports (18). In accordance to recent findings $(19,20)$, the HER2-overexpressing subtype showed the worst OS and DFS, but the survival rate of patients with triple negative carcinomas was not different from that of other groups except for the HER2-overexpressing subtype. The luminal A group of patients showed an unexpectedly low OS and DFS. As in our study, this subgroup showed a high metastasis frequency $(33.3 \%)$ as compared to the other subgroups and displayed a high proliferation score. These features may have contributed to the observed worse prognosis.

In contrast to results of Al-Hajj et al (9) reporting CD44 ${ }^{+} /$ CD24- cells in all breast carcinomas studied, our evaluation of the conventional stem cell phenotype (CD44 $\left.4^{+} / \mathrm{CD} 24^{-}\right)$indicated that only $8.4 \%$ of the analyzed tumors expressed this phenotype. The frequency of stem cells was expected to be low (21) and our frequency rate is lower than those reported by several authors $(11,15,16,22)$. Analysis of several human breast cancer cell lines indicated that this particular phenotype was exhibited by only $25 \%$ (2/8) of the cell lines (23). 
A

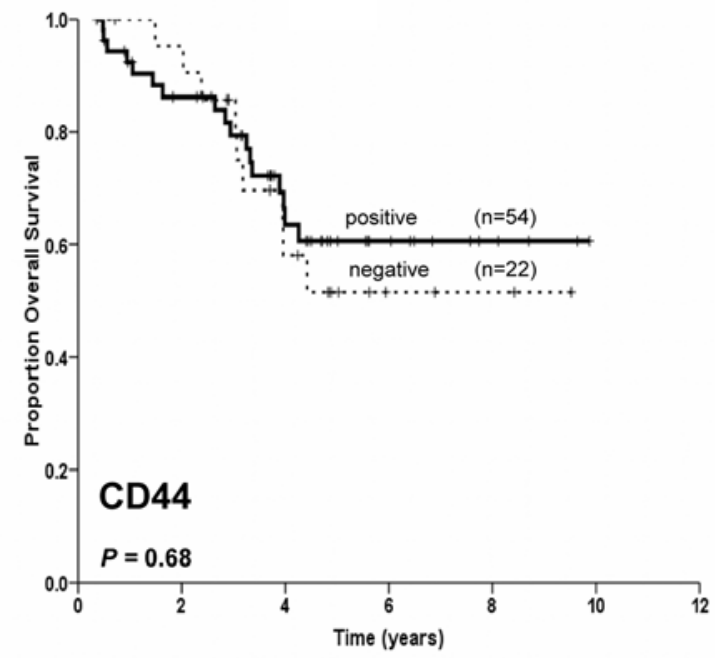

B

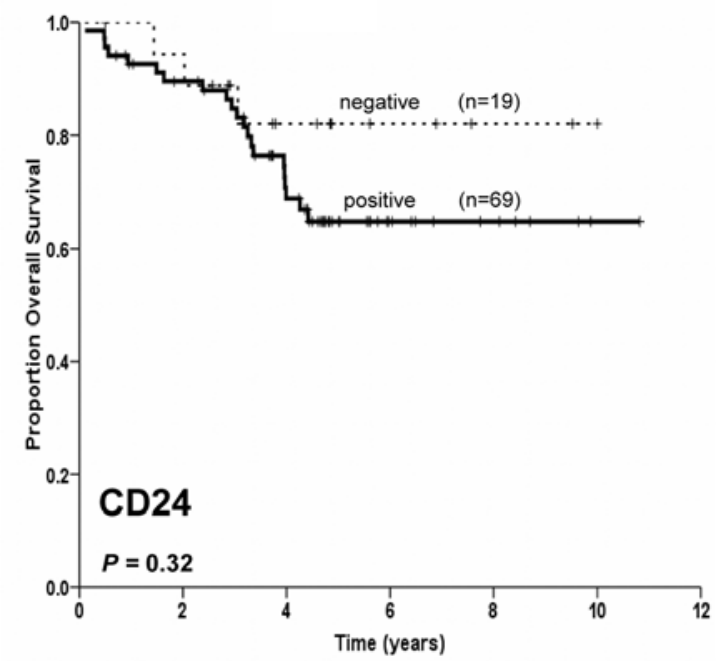

C

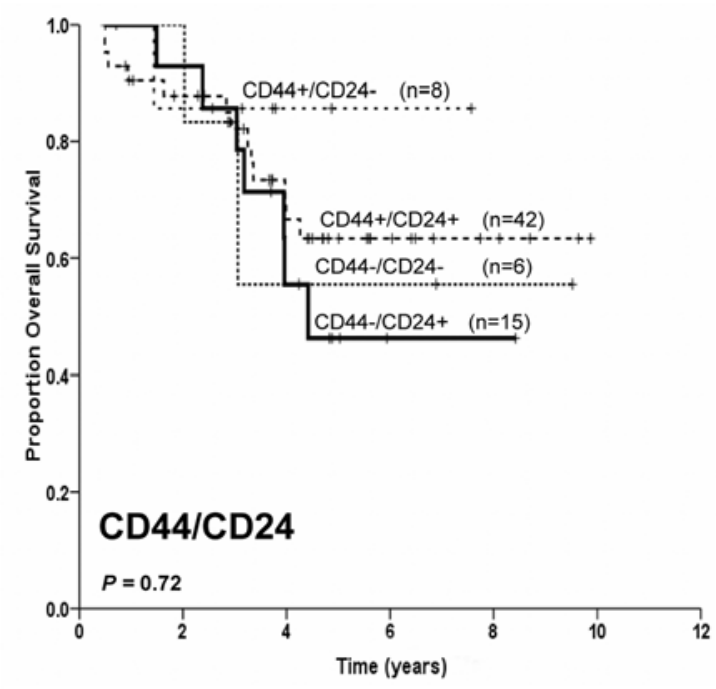

D

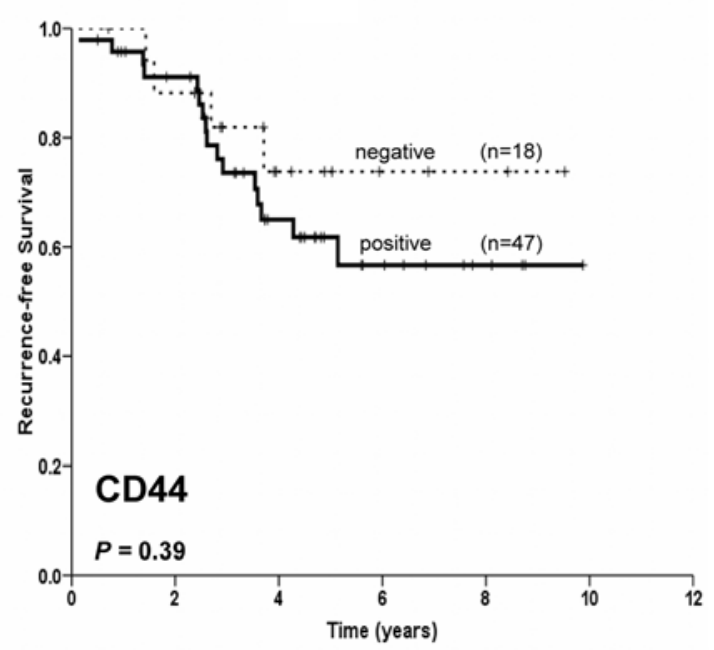

E

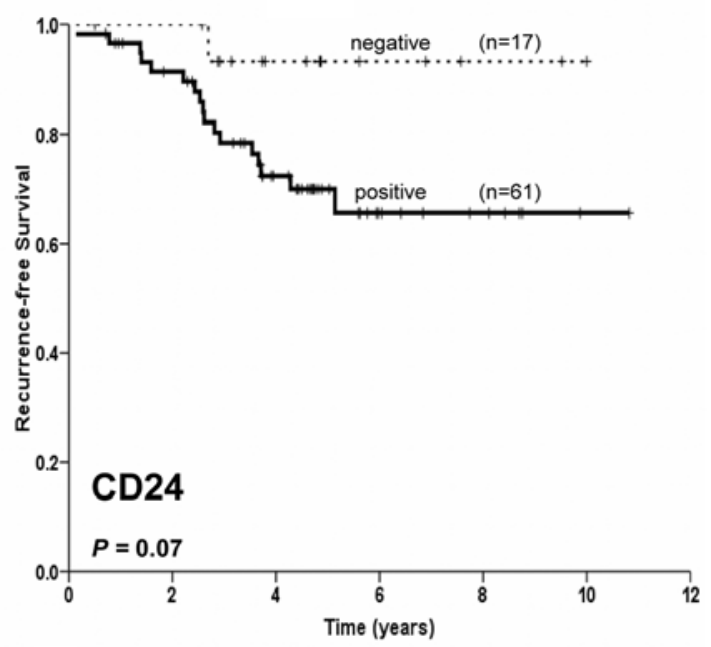

$\mathbf{F}$

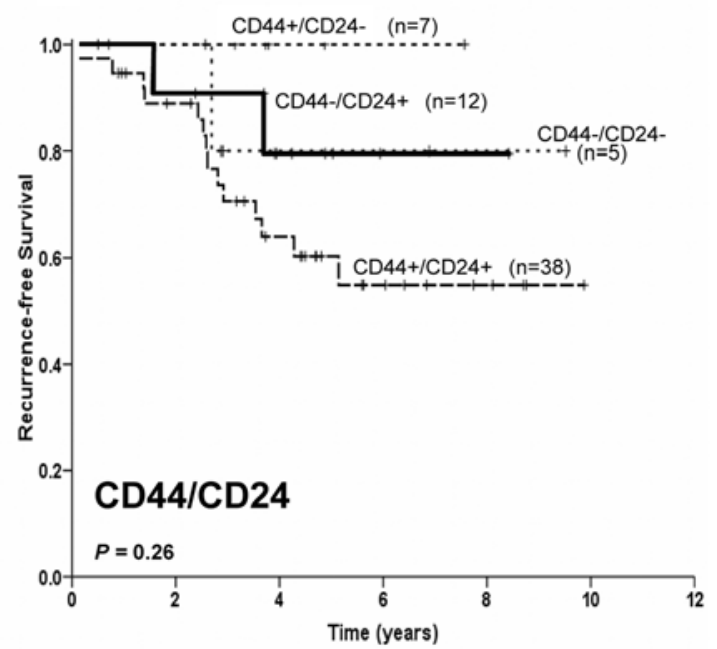

Figure 2. Overall survival and disease-free survival in all patients according to: CD44 (A and D); CD24 (B and E); and CD44/CD24 (C and F).

Several studies have delineated that the $\mathrm{CD}^{2} 4^{+} / \mathrm{CD} 24^{-}$status is associated with the basal-like or triple negative subgroups of breast cancer $(11,12,14,24)$. Although in our study this phenotype was more common in the triple negative subgroups, no statistical significance was seen in the comparison between phenotypes and subgroups. We also did not find an association with known prognostic parameters (pathological stage, nuclear grade and nodal status). Our results confirmed previous reports $(11,15,16)$. 

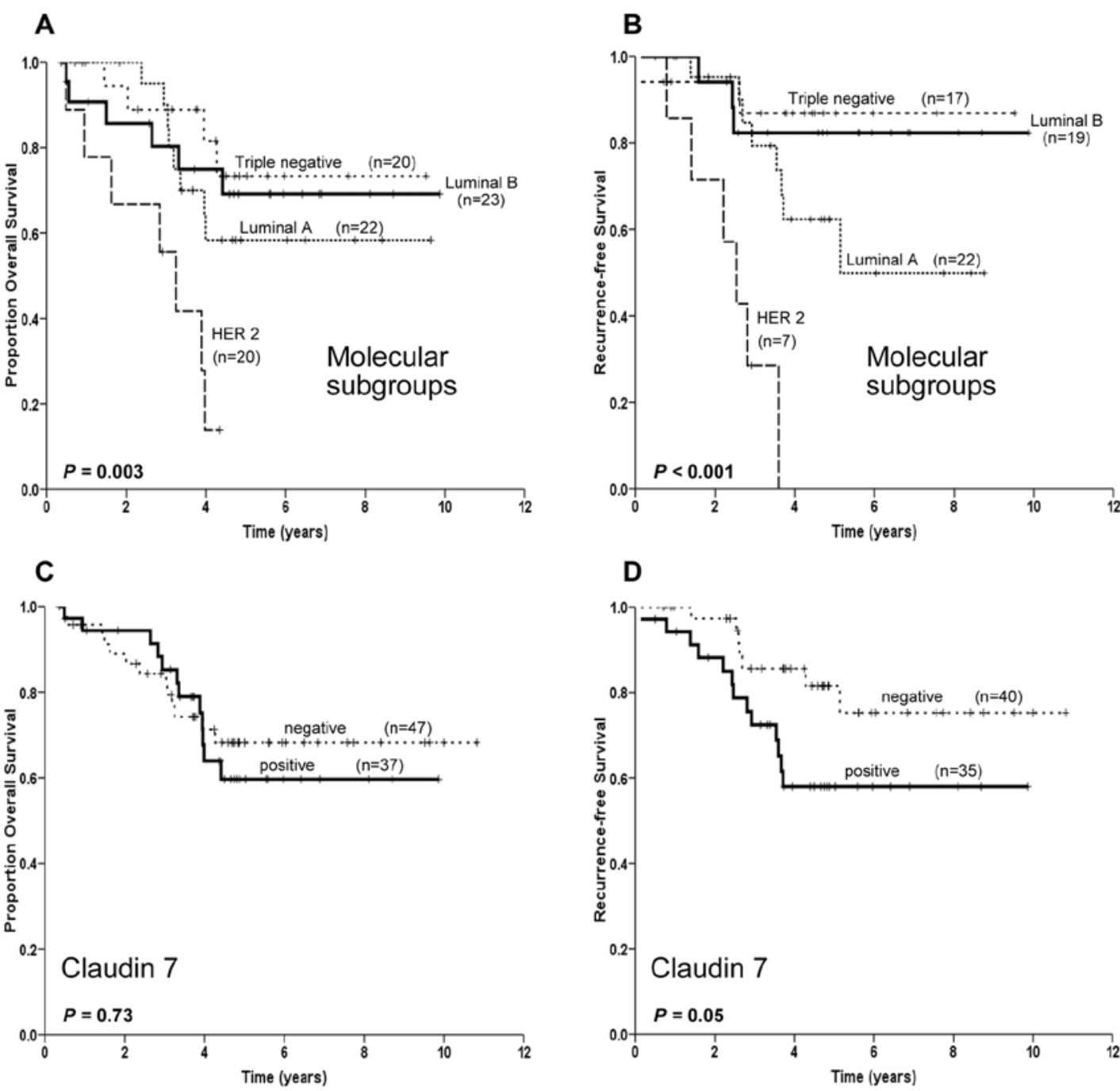

Figure 3. Overall survival and disease-free survival in all patients based on immunohistochemical subgroups (A and B) and claudin-7 (C and D).

Moreover, the HER2 subgroup which in our results presented the worst prognosis in terms of overall survival and disease-free recurrence was negative for the CD44 $/ \mathrm{CD} 24$ phenotype. Similar results have been previously reported suggesting that other markers indicative of a cancer stem cell for HER2 remain to be identified (11).

Other studies have indicated that $\mathrm{CD} 44^{+} / \mathrm{CD} 24^{-}$breast cancer cell lines have highly invasive and metastatic properties $(14,25,26)$ and thus should correlate with poor prognosis. We did not observe any association of $\mathrm{CD} 44^{+} / \mathrm{CD} 24^{-}$in tumors expressing clinicopathological parameters of prognosis or with the potential to progress or recur or with high frequency of metastasis according to other reports $(10,15,16,22,27)$.

In view of these results, we suggest that features of $\mathrm{CD} 44^{+} /$ CD24 tumors in our study are not concordant with tumorigenic properties reported to characterize cancer stem cells (9) and therefore, are consistent with the ones suggesting that $\mathrm{CD} 44^{+} / \mathrm{CD} 24^{-}$may not have the ability to identify cancer stem cells. These results highlight the need of other markers for the evaluation of cancer stem cells. Similar suggestions have been made by Mylona et al (15), Abraham et al (16) and HwangVerslues et al (23).
On the other hand, although the CD44/CD24+ phenotype has failed to identify a statistically significant association with overall survival, we noted a tendency of patients harboring CD44/CD24 $4^{+}$tumors to present a worse prognosis. Moreover, despite the lack of relation to survival we found that CD24 alone was a prognostic indicator of decreased disease-free survival time, confirming results of a recent report (22).

The CD24 protein was expressed in several solid tumors. This protein has been associated with bad disease prognosis and metastatic behavior for several solid tumors including breast cancer (27-30). CD24 $4^{+}$has also been associated with proliferation, adhesion and invasion in MCF-7 cells (31). We verified a statistical association between $\mathrm{CD}_{2} 4^{+}$and $\mathrm{Ki}-67$ $(\mathrm{P}=0.01)$. Therefore, its seems that $\mathrm{CD} 24^{+}$is associated with an aggressive tumor behavior in spite of retaining a differentiated luminal epithelial cell phenotype and our data indicate a significant association between $\mathrm{CD} 24^{+}$with $\mathrm{ER}^{+}, \mathrm{PR}^{+}$and a marginal one with CK18.

Among the proteins analyzed in order to determine the association of its expression with the different phenotypes of breast cancer, claudin-7 expression was noteworthy, as a decreased expression of claudin-7 correlated with higher tumor 
Table VI. Correlation between claudin-7 expression and biological markers and clinicopathological features.

\begin{tabular}{|c|c|c|c|}
\hline \multirow[b]{2}{*}{ Characteristics } & \multicolumn{2}{|c|}{ Claudin-7 expression } & \multirow[b]{2}{*}{ P-value ${ }^{a}$} \\
\hline & $\begin{array}{c}\text { Negative } \\
(\%)\end{array}$ & $\begin{array}{c}\text { Positive } \\
(\%)\end{array}$ & \\
\hline \multicolumn{4}{|l|}{ Stage } \\
\hline $\mathrm{I}+\mathrm{II}$ & $23(57.5)$ & $17(42.5)$ & 1.00 \\
\hline $\mathrm{III}+\mathrm{IV}$ & $26(56.5)$ & $20(43.5)$ & \\
\hline \multicolumn{4}{|l|}{ Nodal status } \\
\hline Positive & $20(62.5)$ & $12(37.5)$ & 0.50 \\
\hline Negative & $28(53.8)$ & $24(46.2)$ & \\
\hline \multicolumn{4}{|l|}{ Nuclear grade } \\
\hline I & $0(0)$ & $2(100.0)$ & 0.21 \\
\hline II & $22(62.9)$ & $13(37.1)$ & \\
\hline III & $27(56.6)$ & $21(43.8)$ & \\
\hline \multicolumn{4}{|l|}{ Metastasis } \\
\hline M0 & $33(60.0)$ & $22(40.0)$ & 0.07 \\
\hline M1 & $7(35.0)$ & $13(65.0)$ & \\
\hline \multicolumn{4}{|c|}{ Estrogen receptor } \\
\hline Positive & $23(52.3)$ & $21(47.7)$ & 0.65 \\
\hline Negative & $20(58.8)$ & $14(41.2)$ & \\
\hline \multicolumn{4}{|c|}{ Progesterone receptor } \\
\hline Positive & $29(65.9)$ & $15(34.1)$ & 0.02 \\
\hline Negative & $14(40.0)$ & $21(60.0)$ & \\
\hline \multicolumn{4}{|l|}{ HER2 } \\
\hline Positive & $14(42.4)$ & $19(57.6)$ & 0.07 \\
\hline Negative & $31(64.6)$ & $17(35.4)$ & \\
\hline \multicolumn{4}{|l|}{$\mathrm{Ki}-67$} \\
\hline Positive & $25(55.6)$ & $20(44.4)$ & 0.82 \\
\hline Negative & $22(59.5)$ & $15(40.5)$ & \\
\hline \multicolumn{4}{|l|}{ CK5 } \\
\hline Positive & $14(82.4)$ & $3(17.6)$ & $\mathbf{0 . 0 3}$ \\
\hline Negative & $32(50.0)$ & $32(50.0)$ & \\
\hline \multicolumn{4}{|l|}{ CK6 } \\
\hline Positive & $1(50.0)$ & $1(50.0)$ & 1.00 \\
\hline Negative & $43(56.6)$ & $33(43.4)$ & \\
\hline \multicolumn{4}{|l|}{ CK18 } \\
\hline Positive & $31(54.4)$ & $26(45.6)$ & 0.64 \\
\hline Negative & $16(61.5)$ & $10(38.5)$ & \\
\hline
\end{tabular}

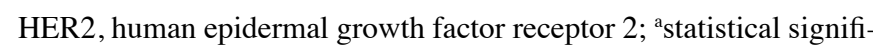
cance was determined by the $\chi^{2}$ test. P-values (two-sided) $<0.05$ were considered statistically significant and are indicated in bold.

grade and metastatic disease (32). Moreover, the claudin ${ }^{\text {low }}$ subtype, which has recently emerged in the molecular classification of breast cancer, is characterized by reduced expression of claudins including claudin-7 (6).

However, we did not find an association between claudin-7 with different phenotypes, or with overall survival. On the other hand, claudin positive carcinomas relapsed more frequently than claudin negative ones, $(\mathrm{P}=0.05)$. Although this observation seems to contradict the hypothesis that claudin ${ }^{\text {low }}$ cells are associated to poor outcome tumors, it is consistent with two recent studies that have highlighted the association of preserved claudin- 4 and claudin-1 with poor prognosis in breast cancer $(33,34)$.

In conclusion, our results suggest that the frequency of CD $44^{+} / \mathrm{CD} 24^{-}$tumor cells in breast cancer may not be associated to outcome. Both CD24 and claudin-7 positivity were associated to reduced time of recurrence suggesting that these two investigated markers can be used in combinations with other clinicopathological information to improve the assessment of prognosis in breast carcinoma.

\section{Acknowledgements}

This study was supported by FAPESP and CNPq. The authors acknowledge the kind assistance of Dr Rafael Malagoli (Department of Pathology of Hospital A.C. Camargo).

\section{References}

1. Weigelt B, Geyer FC, Horlings HM, Kreike B, Halfwerk H and Reis-Filho JS: Mucinous and neuroendocrine breast carcinomas are transcriptionally distinct from invasive ductal carcinomas of no special type. Mod Pathol 22: 1401-1414, 2009.

2. Perou CM, Sorlie T, Eisen MB, et al: Molecular portraits of human breast tumours. Nature 406: 747-752, 2000.

3. Carey LA, Perou CM, Livasy CA, et al: Race, breast cancer subtypes and survival in the Carolina Breast Cancer Study. JAMA 295: 2492-2502, 2006.

4. Weigelt B, Baehner FL and Reis-Filho JS: The contribution of gene expression profiling to breast cancer classification, prognostication and prediction: a retrospective of the last decade. J Pathol 220: 263-280, 2010.

5. Cheang MC, Chia SK, Voduc D, et al: Ki-67 index, HER2 status, and prognosis of patients with luminal B breast cancer. J Natl Cancer Inst 101: 736-750, 2009.

6. Prat A, Parker JS, Karginova O, et al: Phenotypic and molecular characterization of the claudin-low intrinsic subtype of breast cancer. Breast Cancer Res 12: R68, 2010.

7. Dontu G, Al-Hajj M, Abdallah WM, Clarke MF and Wicha MS: Stem cells in normal breast development and breast cancer. Cell Prolif 1: 59-72, 2003.

8. Smalley M and Ashworth A: Stem cells and breast cancer: a field in transit. Nat Cancer 3: 832-844, 2003.

9. Al-Hajj M, Wicha MS, Benito-Hernandez A, Morrison SJ and Clarke MF: Prospective identification of tumorigenic breast cancer cells. Proc Natl Acad Sci USA 100: 3983-3988, 2003.

10. Shipitsin M, Campbell LL, Argani P, et al: Molecular definition of breast tumor heterogeneity. Cancer Cell 11: 259-273, 2007.

11. Honeth G, Bendahl PO, Ringnér M, et al: The CD $44^{+} / \mathrm{CD} 24$ phenotype is enriched in basal-like breast tumors. Breast Cancer Res 10: R53, 2008.

12. Park SY, Lee HE, Li H, Shipitsin M, Gelman R and Polyak K: Heterogeneity for stem cell-related markers according to tumor subtype and histologic stage in breast cancer. Clin Cancer Res 16: 876-887, 2010

13. Giatromanolaki A, Sivridis E, Fiska A and Koukourakis MI: The $\mathrm{CD} 44^{+} / \mathrm{CD} 24^{-}$phenotype relates to 'triple-negative' state and unfavorable prognosis in breast cancer patients. Med Oncol 28: 745-752, 2011.

14. Sheridan C, Kishimoto H, Fuchs RK, et al: CD44+CD24-breast cancer cells exhibit enhanced invasive properties: an early step necessary for metastasis. Breast Cancer Res 8: R59, 2006.

15. Mylona E, Giannopoulou I, Fasomytakis E, Nomikos A, Magkou C, Bakarakos P and Nakopoulou L: The clinicopathologic and prognostic significance of CD44+/CD24(-/low) and CD $44^{-} / \mathrm{CD} 24^{+}$tumor cells in invasive breast carcinomas. Hum Pathol 39: 1096-1102, 2008. 
16. Abraham BK, Fritz P, McClellan M, Hauptvogel P, Athelogou M and Brauch $\mathrm{H}$ : Prevalence of $\mathrm{CD} 44^{+} / \mathrm{CD} 24^{-1 \text { low }}$ cells in breast cancer may not be associated with clinical outcome but may favor distant metastasis. Clin Cancer Res 11: 1154-1159, 2005.

17. Allred DC, Harvey JM, Berardo M, et al: Prognostic and predictive factors in breast cancer by immunohistochemical analysis. Mod Pathol 11: 155-168, 1998.

18. Yang XR, Sherman ME, Rimm DL, et al: Differences in risk factors for breast cancer molecular subtypes in a populationbased study. Cancer Epidemiol Biomarkers Prev 16: 439-443, 2007.

19. Prat A and Perou CM: Deconstructing the molecular portraits of breast cancer. Mol Oncol 5: 5-23, 2011.

20. Pal SK, Childs BH and Pegram M: Triple negative breast cancer: unmet medical needs. Breast Cancer Res Treat 125: 627-636, 2011.

21. Hill RP: Identifying cancer stem cells in solid tumors: case not proven. Cancer Res 66: 1891-1895, 2006.

22. Kim HJ, Kim MJ, Ahn SH, et al: Different prognostic significance of CD24 and CD44 expression in breast cancer according to hormone receptor status. Breast 20: 78-85, 2011.

23. Hwang-Verslues WW, Kuo WH, Chang PH, et al: Multiple lineages of human breast cancer stem/progenitor cells identified by profiling with stem cell markers. PLoS One 4: e8377, 2009.

24. Klingbeil P, Natrajan R, Everitt G, et al: CD44 is overexpressed in basal-like breast cancers but is not a driver of $11 \mathrm{p} 13$ amplification. Breast Cancer Res Treat 120: 95-109, 2010.

25. Meyer MJ, Fleming JM, Ali MA, Pesesky MW, Ginsburg E and Vonderhaar BK: Dynamic regulation of CD24 and the invasive, CD44posCD24neg phenotype in breast cancer cell lines. Breast Cancer Res 11: R82, 2009.
26. Pandit TS, Kennette W, Mackenzie L, et al: Lymphatic metastasis of breast cancer cells is associated with differential gene expresion profiles that predict cancer stem cell-like properties and the ability to survive, establish and grow in a foreign environment. Int J Oncol 35: 297-308, 2009.

27. Diaz LK, Zhou X, Wright, et al: CD44 expression is associated with increased survival in node-negative invasive breast carcinoma. Clin Cancer Res 11: 3309-3314, 2005.

28. Kristiansen G, Winzer KJ, Mayordomo E, et al: CD24 expression is a new prognostic marker in breast cancer. Clin Cancer Res 9: 4906-4913, 2003.

29. Lim SC and Oh SH: The role of CD24 in various human epithelial neoplasias. Pathol Res Pract 201: 479-486, 2005.

30. Baumann P, Cremers N, Kroese F, et al: CD24 expression causes the acquisition of multiple cellular properties associated with tumor growth and metastasis. Cancer Res 65: 10783-10793, 2005.

31. Kim HJ, Kim JB, Lee, et al: Isolation of CD24(high) and CD24(low/-) cells from MCF-7: CD24 expression is positively related with proliferation, adhesion and invasion in MCF-7. Cancer Lett 258: 98-108, 2007.

32. Szasz AM, Tokes AM, Micsinai, et al: Prognostic significance of claudin expression changes in breast cancer with regional lymph node metastasis. Clin Exp Metastasis 28: 55-63, 2011.

33. Lanigan F, McKiernan E, Brennan DJ, et al: Increased claudin-4 expression is associated with poor prognosis and high tumour grade in breast cancer. Int J Cancer 124: 2088-2097, 2009.

34. Myal Y, Leygue E and Blanchard AA: Claudin 1 in breast tumorigenesis: revelation of a possible novel 'claudin high' subset of breast cancers. J Biomed Biotechnol 2010: 956897, 2010. 